\title{
Combined analysis of C-18 unsaturated fatty acids using Natural Abundance Deuterium 2D NMR Spectroscopy in Chiral Oriented solvents
}

\section{Philippe Lesot, ${ }^{a, *}$ Vincent Baillif $^{b}$ and Isabelle Billault ${ }^{b}$}

${ }^{\boldsymbol{a}}$ Université de Paris-Sud (XI), ICMMO, UMR CNRS 8182, Laboratoire de Chimie Structurale Organique, Equipe de RMN en Milieu Orienté, UFR des sciences d'Orsay, Bât. 410, 91405 Orsay Cedex, France.

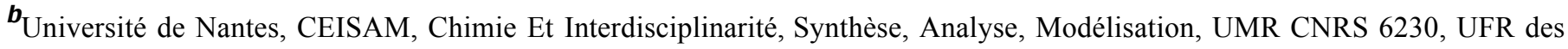
Sciences et des Techniques, 2, rue de la Houssinière, BP 92208, 44322 NANTES Cedex 3, France.

RECEIVED DATE (to be automatically inserted after your manuscript is accepted if required according to the journal that you are submitting your paper to)

*To whom correspondence should be addressed: Dr. Philippe Lesot, Tel.: +33 (0)1 6947 59, Fax: +33 (0)1 691581 05, E-mail: philesot@icmo.u-psud.fr

\section{DATA FOR SUPPLEMENTARY INFORMATION}

\section{List of Data :}

Figure SI-1. Pulse sequence of (a) the $Q$-COSY Fz and (b) the $Q$-resolved Fz 2D experiment.

Figure SI-2. $92.1 \mathrm{MHz}{ }^{2} \mathrm{H}-\left\{{ }^{1} \mathrm{H}\right\}$ isotropic 1D spectrum of methyl linoleate 2 recorded in quantitative conditions.

Figure SI-3. 92.1 MHz NAD $Q$-COSY Fz 2D spectrum of methyl linoleate 2 dissolved in PBLG/CHCl 3 .

Figure SI-4. Series of ${ }^{2} \mathrm{H}-\left\{{ }^{1} \mathrm{H}\right\}$ 1D subspectra extracted from the tilted $Q$-COSY Fz map of methyl linoleate 2 dissolved in $\mathrm{PBG} / \mathrm{CHCl}_{3}$.

Figure SI-5. Comparison of the $\Delta v_{\mathrm{Q}}$ 's (absolute value) of methyl linoleate 2 dissolved in PBLG, PBG and PBDG mesophases versus the deuterium sites (1 to 18).

Figure SI-6. Series of ${ }^{2} \mathrm{H}-\left\{{ }^{1} \mathrm{H}\right\}$ 1D sub-spectra extracted from the tilted $Q$-COSY Fz map of (a) methyl oleate $\mathbf{1}$ and (b) methyl linolenate 3 both dissolved in the $\mathrm{PBLG} / \mathrm{CHCl}_{3}$ mesophase.

Figure SI-7. Zoom (on the aliphatic region) on the tilted $Q$-COSY Fz map of methyl oleate 1 dissolved in $\mathrm{PBLG}^{\mathrm{C}} \mathrm{CHCl}{ }_{3}$ and $\mathrm{PBG} / \mathrm{CHCl}_{3}$.

Figure SI-8. Zoom (on the aliphatic region) on the tilted $Q$-COSY Fz map of methyl linoleate 2 dissolved in $\mathrm{PBLG} \mathrm{CHCl}{ }_{3}$ and $\mathrm{PBG} / \mathrm{CHCl}_{3}$.

Figure SI-9. Zoom (on the aliphatic region) on the tilted $Q$-COSY Fz map of methyl linolenate 3 dissolved in $\mathrm{PBLG} / \mathrm{CHCl}_{3}$ and $\mathrm{PBG} / \mathrm{CHCl}_{3}$.

Figure SI-10. Zoom (on the aliphatic region) on the tilted $Q$-COSY Fz map of methyl vernoleate 4 dissolved in $\mathrm{PBLG} / \mathrm{CHCl}_{3}$ and $\mathrm{PBG} / \mathrm{CHCl}_{3}$.

Figure SI-11. Zoom on the ethylenic region of the tilted $Q$-COSY Fz map of (a) methyl linoleate 2 and (b) methyl linolenate 3, both dissolved in $\mathrm{PBG} / \mathrm{CHCl}_{3}$ mesophase at $300 \mathrm{~K}$.

Figure SI-12. Lowest-energy conformer for the methyl oleate $\mathbf{1}$, the methyl isolate $\mathbf{2}$, the methyl linolenate $\mathbf{3}$ and the methyl vernoleate 4 . 


\section{List of Tables :}

Table SI-1. Quadrupolar splittings of each deuterium site in compounds $\mathbf{1}$ to $\mathbf{4}$ dissolved in the PBLG and PBG mesophases.

Table SI-2. Quadrupolar splittings of all unequivalent deuterium sites of 2 dissolved in PBLG, PBG and PBDG mesophases.

Table SI-3. $\left({ }^{2} \mathrm{H} /{ }^{1} \mathrm{H}\right)_{\mathrm{i}}$ ratios measured for methyl linoleate 2 dissolved in $\mathrm{PBLG} / \mathrm{CHCl}_{3}$ (with $\mathrm{T}_{\mathrm{R}}: 1 \mathrm{sec}$ ) and using the isotropic SNIF-NMR.

Table SI-4. Composition of liquid-crystalline NMR samples.

(a)

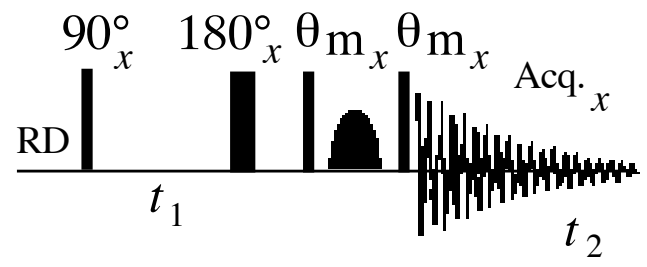

z-gradient filter
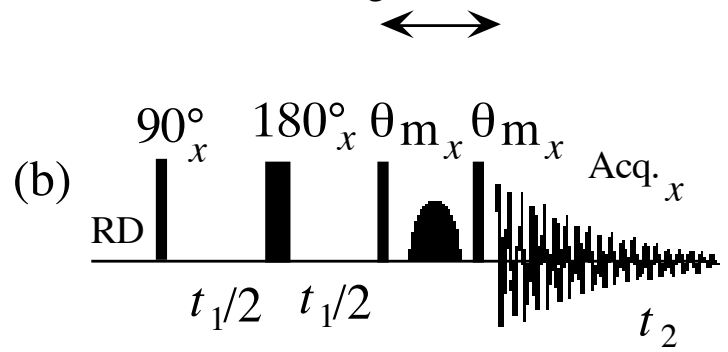

Figure SI-1. Pulse sequence of (a) the $Q$-COSY Fz and (b) the $Q$-resolved Fz $2 \mathrm{D}$ experiment. Note the presence of z-gradient filter $\left(\theta_{\mathrm{m}}=54.7^{\circ}\right)$ inserted prior to the $t_{2}$ acquisition period. The protons are decoupled during all the duration of the experiment using the WALTZ-16 sequence.

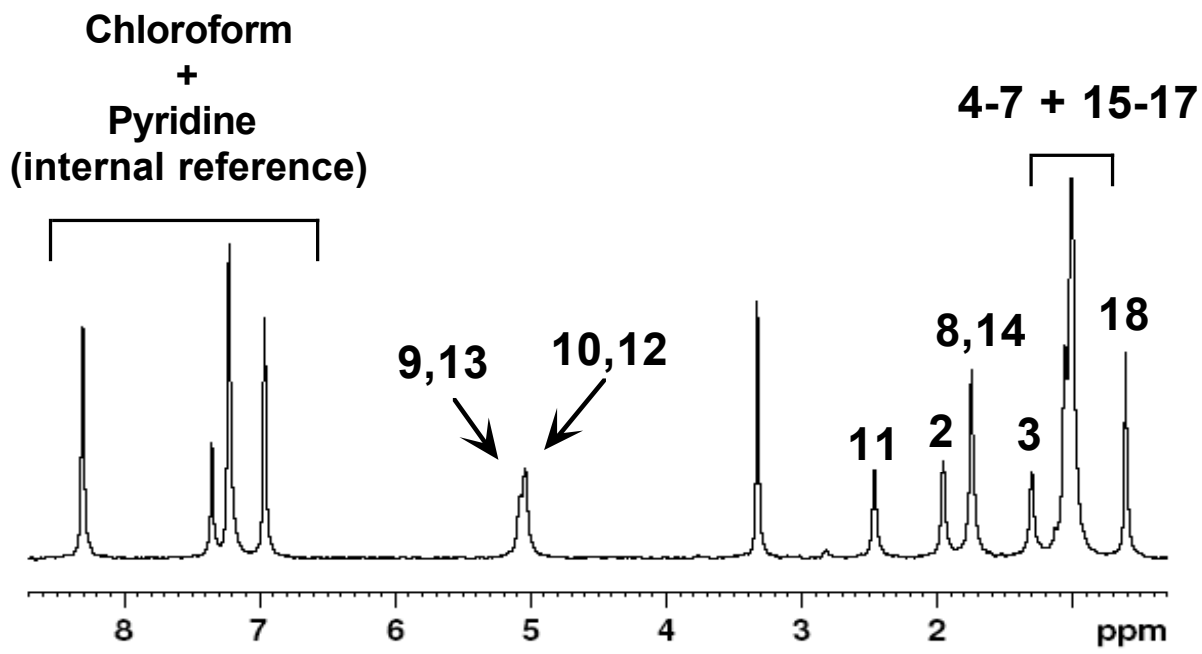

Figure SI-2. $92.1 \mathrm{MHz}{ }^{2} \mathrm{H}-\left\{{ }^{1} \mathrm{H}\right\}$ isotropic 1D spectrum of methyl linoleate 2 recorded in quantitative conditions. Note the superposition of numerous deuterium signals in the aliphatic region, and the presence of pyridine peak used as internal reference for the $(2 \mathrm{H} / 1 \mathrm{H})_{\mathrm{i}}$ measurement. This $1 \mathrm{D}$ spectrum was recorded in five hours $(\mathrm{NS}=30000$ scans $)$ with an ${ }^{2} \mathrm{H}$ cryoprobe. Exponential filtering $(\mathrm{LB}=1 \mathrm{~Hz})$ is applied prior to Fourier transformation. 


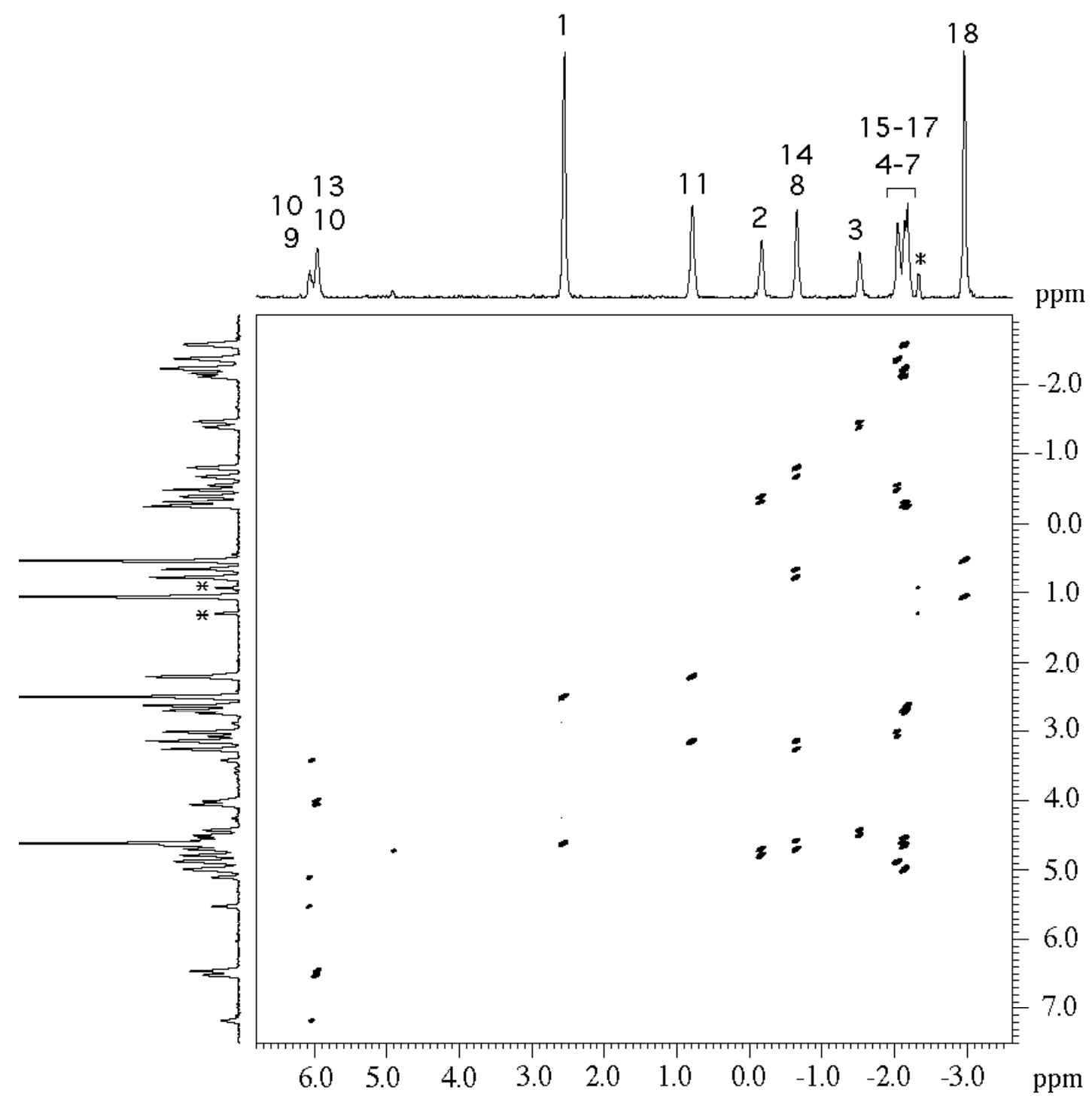

Figure SI-3. 92.1 MHz NAD $Q$-COSY Fz 2D spectrum of methyl linoleate 2 dissolved in $\mathrm{PBLG} / \mathrm{CHCl}_{3}$ phase and recorded at $300 \mathrm{~K}$. The number of scans for each $t_{1}$ increment is 96 . The recycling delay was of $1 \mathrm{~s}$ repetition time. The $2 \mathrm{D}$ map is symmetrized and a tilt procedure then applied. Peaks labeled with an asterisk correspond to the methyl signal of ethanol using for stabilizing chloroform. The scale (in $\mathrm{ppm}$ ) in the $F_{2}$ dimension has no chemical meaning (see ref. 23). 

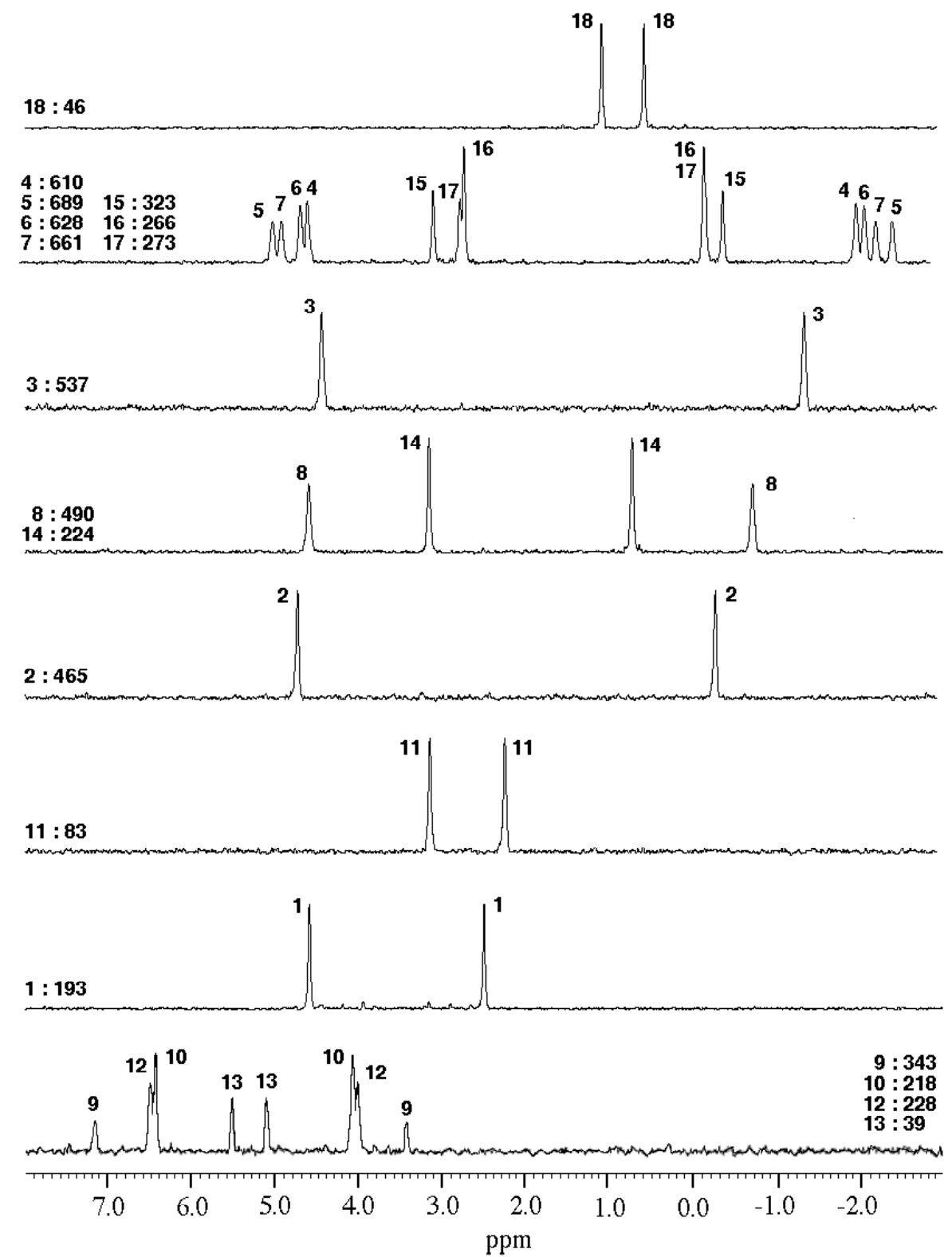

Figure SI-4. Series of ${ }^{2} \mathrm{H}-\left\{{ }^{1} \mathrm{H}\right\}$ 1D subspectra extracted from the tilted $Q$-COSY Fz map of methyl linoleate 2 dissolved in $\mathrm{PBG} / \mathrm{CHCl}_{3}$ at $300 \mathrm{~K}$. The value of quadrupolar splittings are given in $\mathrm{Hz}$. 


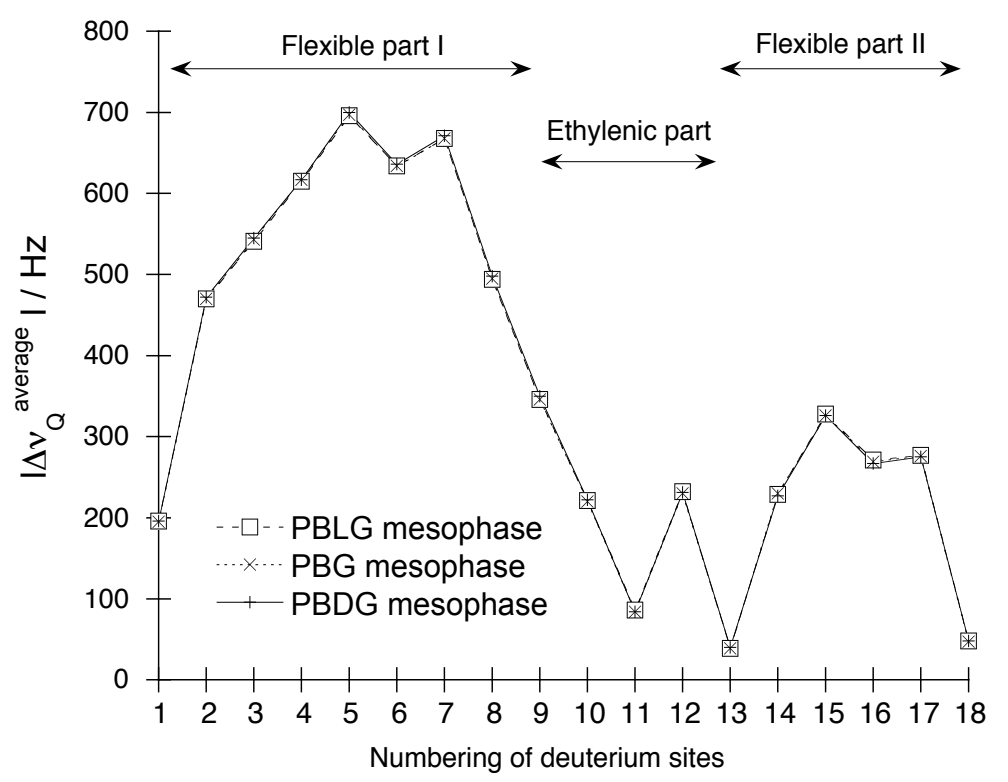

Figure SI-5. Comparison of the $\Delta v_{\mathrm{Q}}$ 's (absolute value) of methyl linoleate $\mathbf{2}$ dissolved in PBLG, PBG and PBDG mesophases versus the deuterium sites (1 to 18). In PBLG and PBDG solvents, the average value of $\Delta v_{\mathrm{Q}}$ 's for the methylene sites that are spectrally discriminated are reported on graph. ${ }^{2} \mathrm{H}$ data recorded PBG and PBDG have been normalized relative to PBLG data in order to be correctly compared. The values in PBG and PBDG were corrected relative to values measured in PBLG (see ref. 16).

(a)

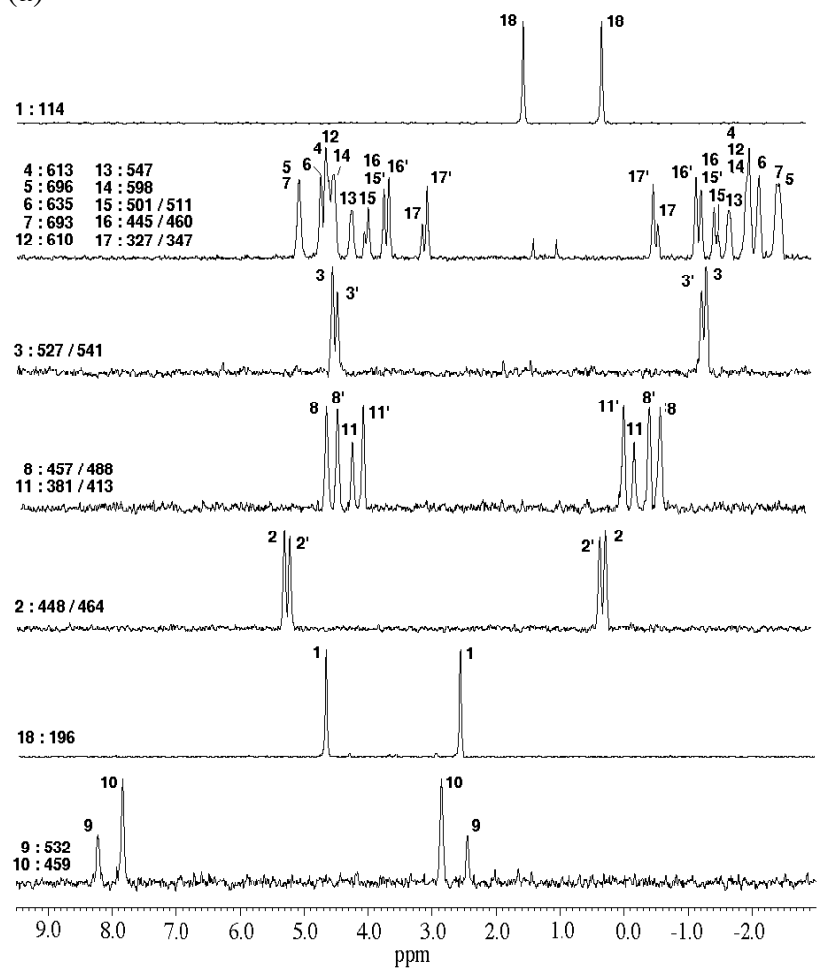

(b)
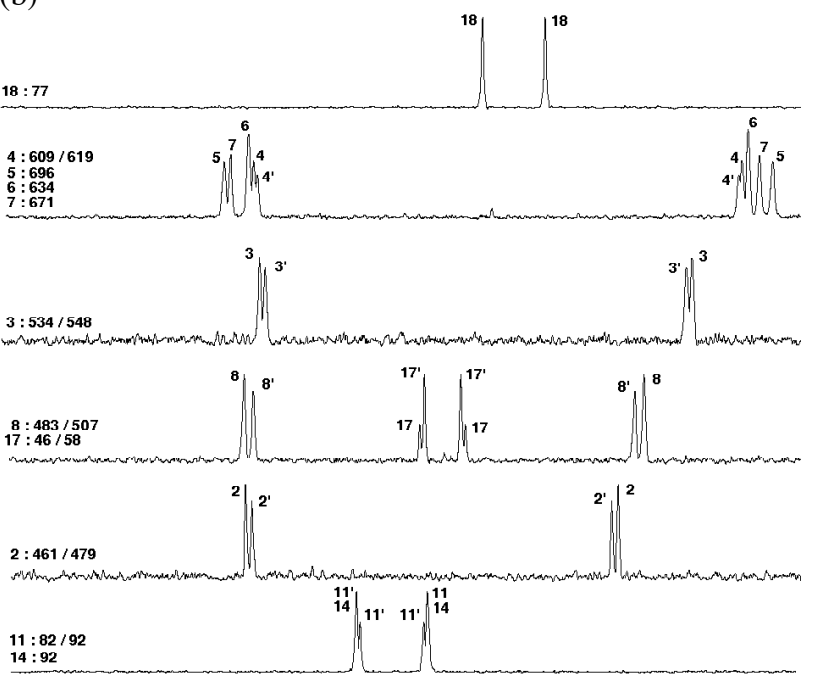

$11: 82 / 92$
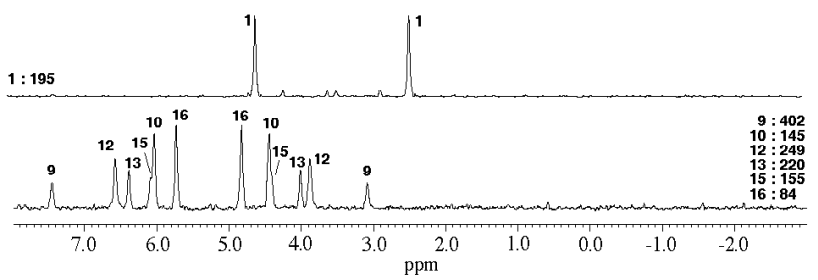

Figure SI-6. Series of ${ }^{2} \mathrm{H}-\left\{{ }^{1} \mathrm{H}\right\}$ 1D sub-spectra extracted from the tilted $Q$-COSY Fz map of (a) methyl oleate 1 and (b) methyl linolenate 3 both dissolved in the PBLG/CHCl 3 mesophase and recorded at $300 \mathrm{~K}$. Zooms of $2 \mathrm{D}$ maps are reported below. 
(a)

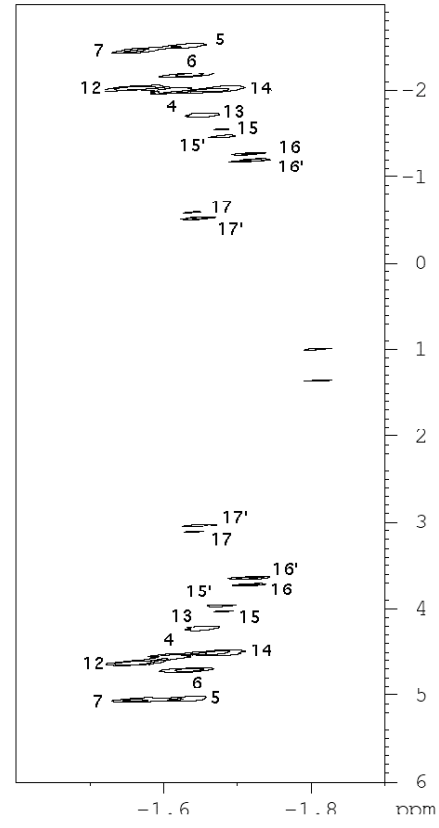

(b)

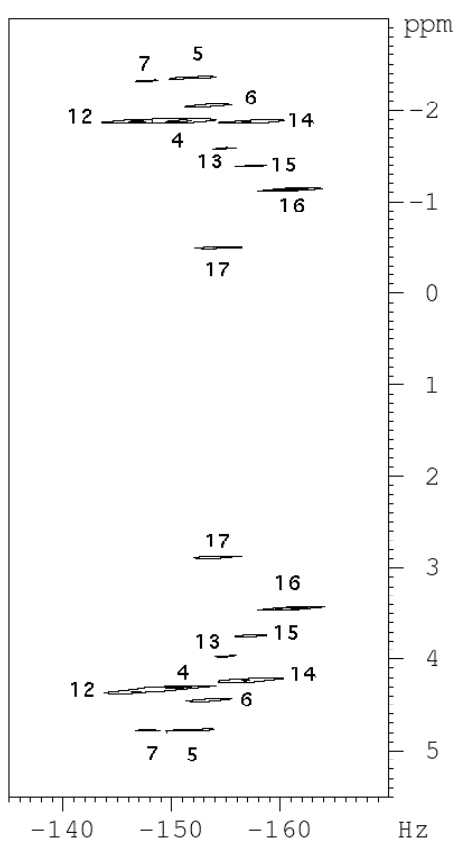

Figure SI-7. Zoom on the aliphatic region of the tilted $Q$-COSY Fz map of methyl oleate 1 dissolved in (a) $\mathrm{PBLG} / \mathrm{CHCl}_{3}$ and (b) $\mathrm{PBG} / \mathrm{CHCl}_{3}$ at $300 \mathrm{~K}$.

(a)

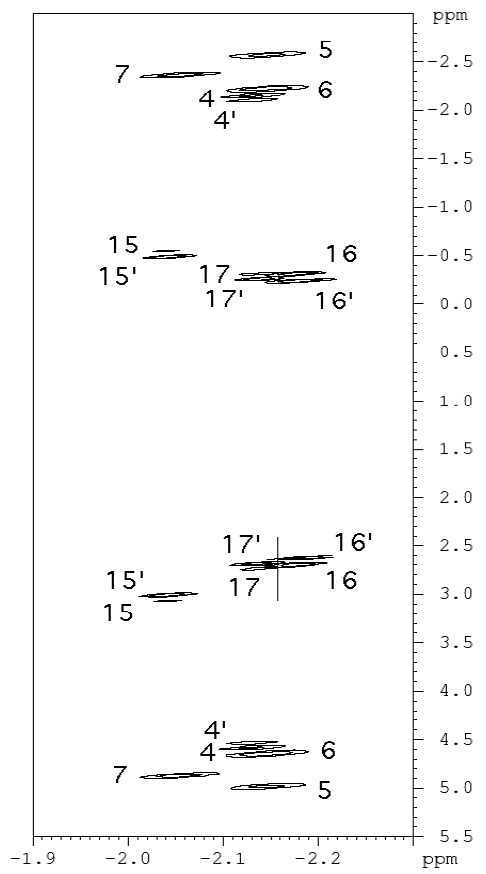

(b)

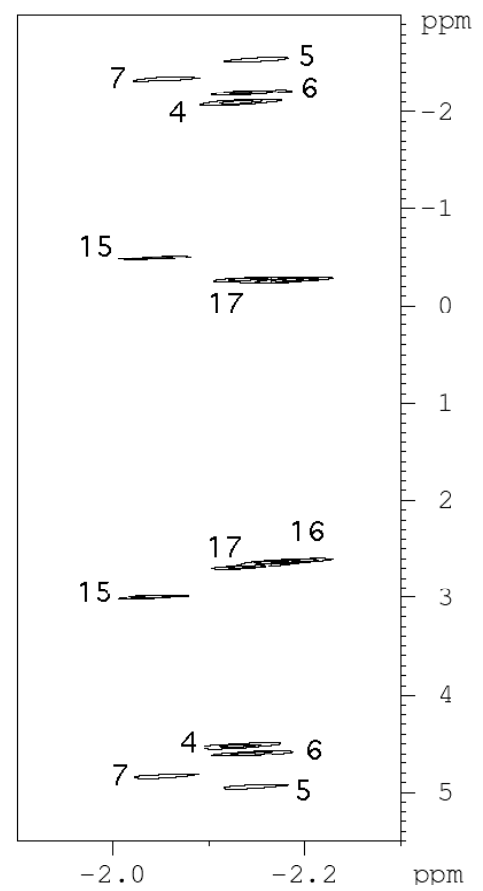

Figure SI-8. Zoom (on the aliphatic region) on the tilted $Q$-COSY Fz map of methyl linoleate 2 dissolved in (a) $\mathrm{PBLG} / \mathrm{CHCl}_{3}$ and (b) $\mathrm{PBG} / \mathrm{CHCl}_{3}$ at $300 \mathrm{~K}$. 
(a)

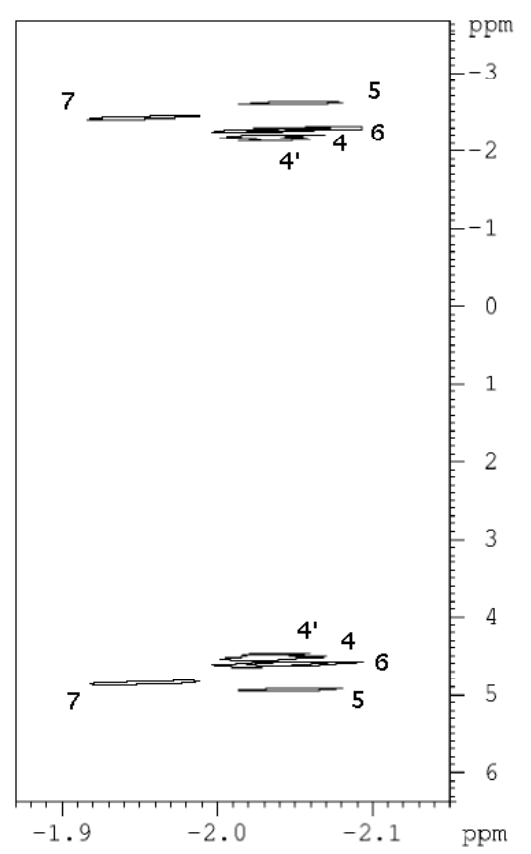

(b)

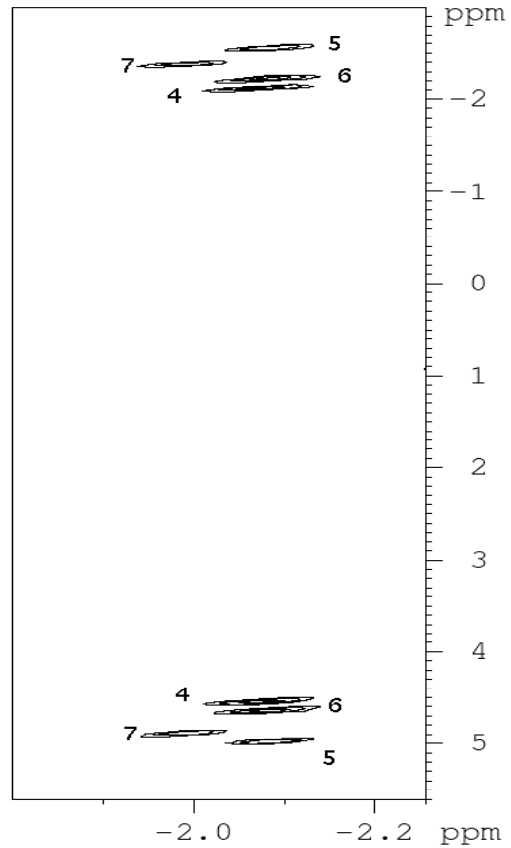

Figure SI-9. Zoom (on the aliphatic region) on the tilted $Q$-COSY Fz map of methyl linolenate 3 dissolved in (a) $\mathrm{PBLG} / \mathrm{CHCl}_{3}$ and (b) $\mathrm{PBG} / \mathrm{CHCl}_{3}$ at $300 \mathrm{~K}$.

(a)

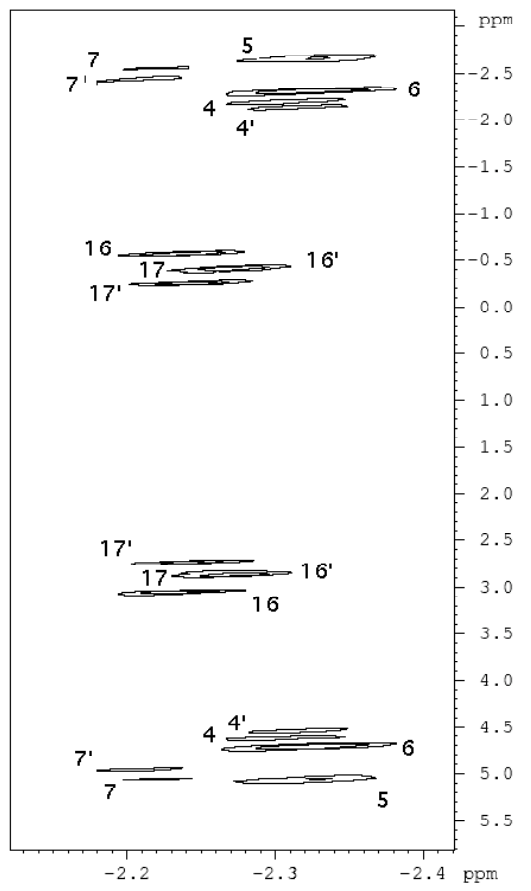

(b)

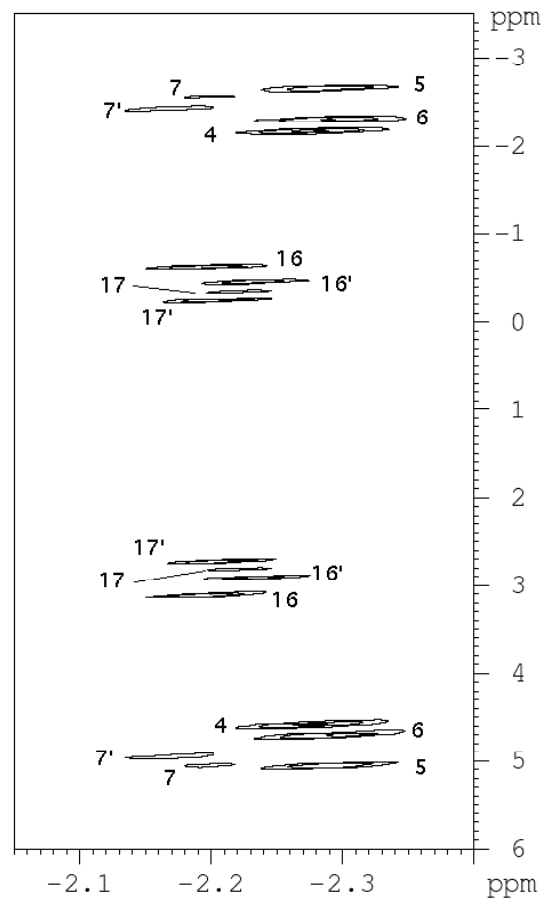

Figure SI-10. Zoom (on the aliphatic region) on the tilted $Q$-COSY Fz map of methyl vernoleate 4 dissolved in (a) PBLG/CHCl 3 and (b) $\mathrm{PBG} / \mathrm{CHCl}_{3}$ at $300 \mathrm{~K}$. 
(a)

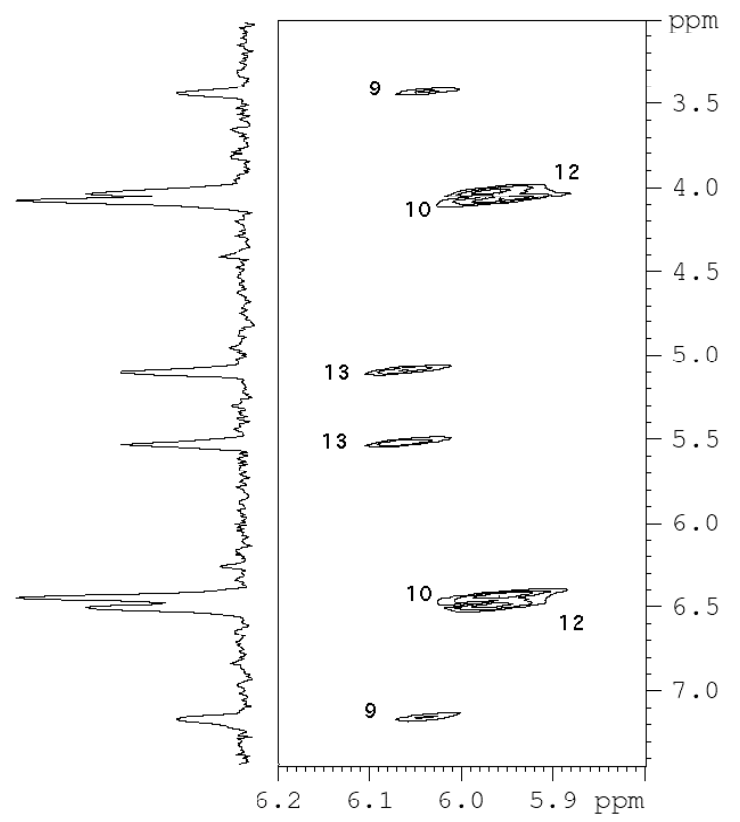

(b)

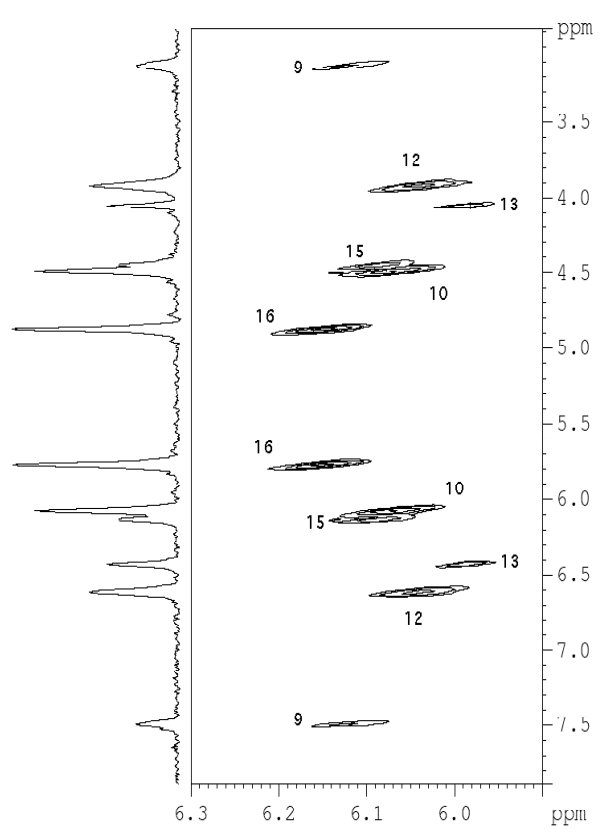

Figure SI-11. Zoom (on the ethylenic region) on the tilted $Q$-COSY Fz map of (a) methyl linoleate 2 and (b) methyl linolenate 3, both dissolved in $\mathrm{PBG} / \mathrm{CHCl}_{3}$ mesophase at $300 \mathrm{~K}$.

(a)

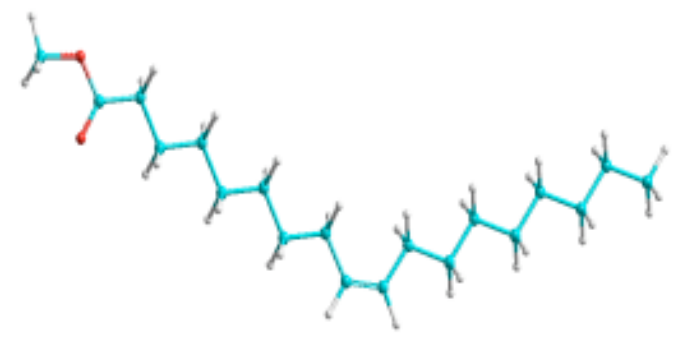

Methyl oleate

(c)

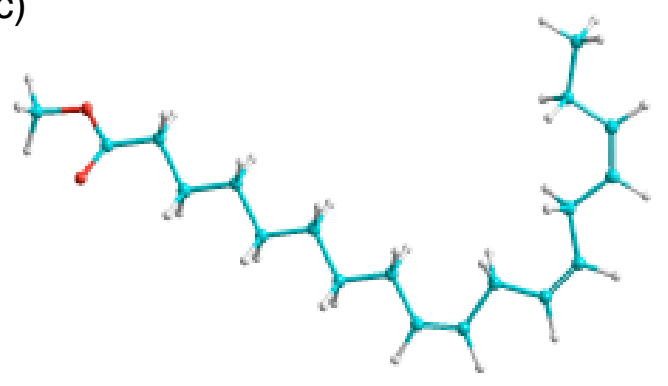

(b)

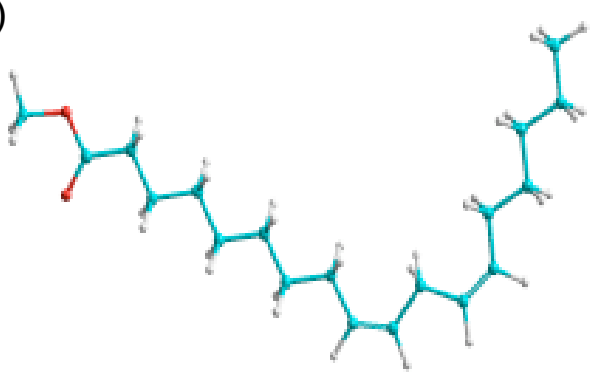

Methyl linoleate

(d)

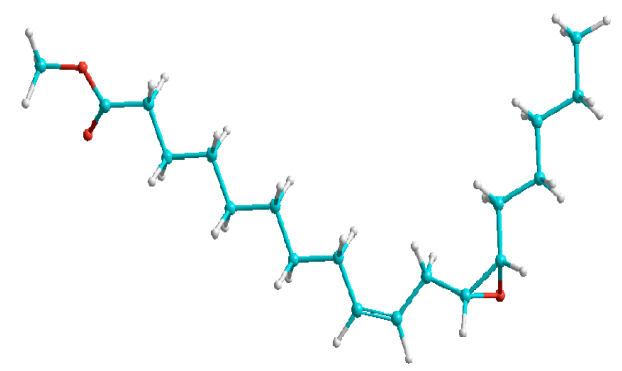

Methyl vernoleate

Figure SI-12. Lowest-energy conformer for (a) the methyl oleate 1, (b) the methyl linoleate $\mathbf{2}$, (c) the methyl linolenate $\mathbf{3}$ and (d) the methyl vernoleate $\mathbf{4}$ determined by molecular modelling using Hyperchem 5.0 software. The calculation uses the semiemprical model (AM1) and the Polack-Ribiere algorithm. 


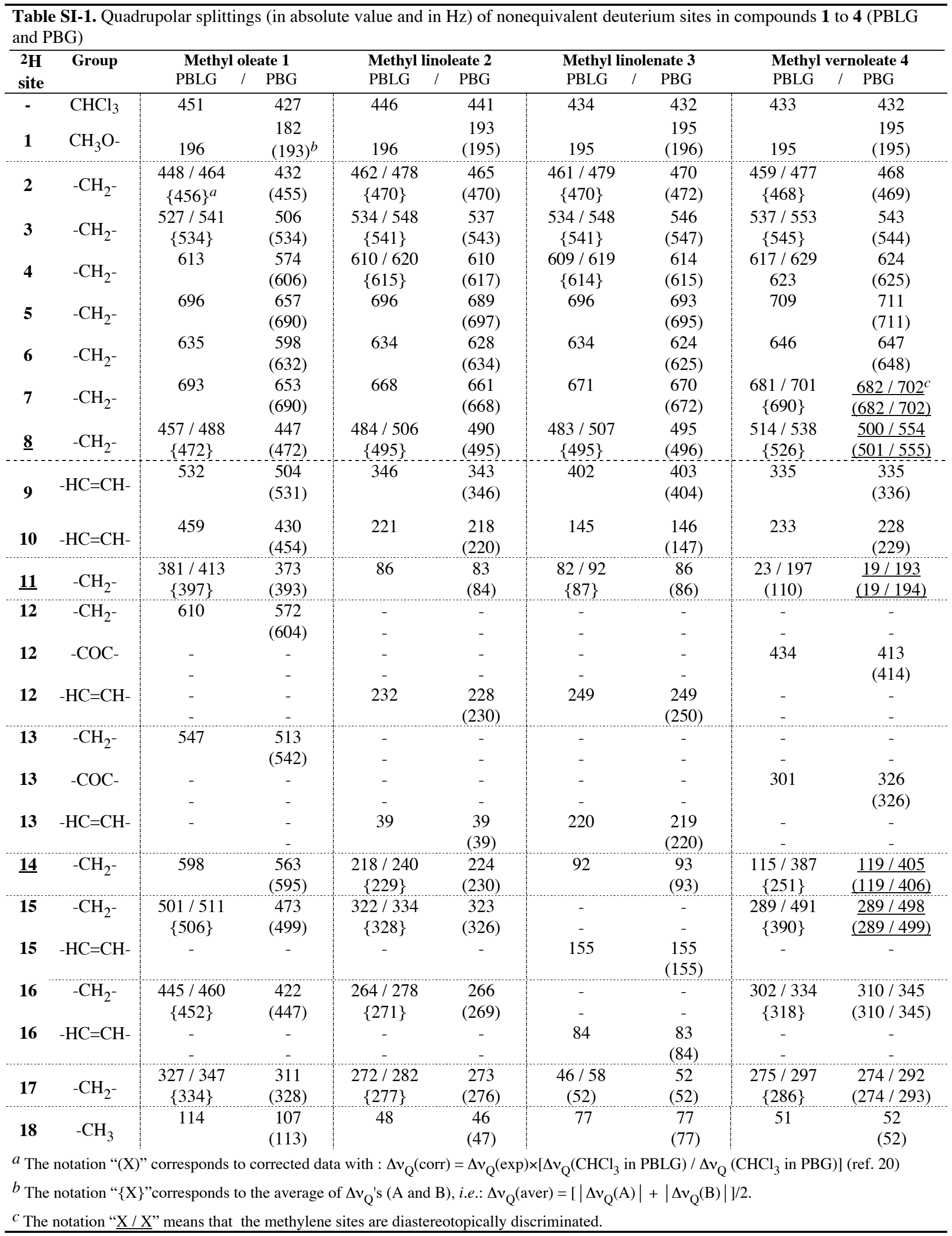


Table SI-3. $\left({ }^{2} \mathrm{H} /{ }^{1} \mathrm{H}\right)_{\mathrm{i}}$ ratios (in ppm) measured for methyl linoleate $\mathbf{2}$ dissolved in $\mathrm{PBLG} / \mathrm{CHCl}_{3}\left(\right.$ with $\left.\mathrm{T}_{\mathrm{R}}=1 \mathrm{sec}\right)$ and using isotropic SNIF-NMR

\begin{tabular}{|c|c|c|c|c|c|c|c|c|c|}
\hline \multirow[b]{2}{*}{${ }^{2} \mathrm{H}$ site } & \multicolumn{7}{|c|}{ Anisotropic medium } & \multicolumn{2}{|c|}{ Isotropic medium } \\
\hline & $\begin{array}{c}\left({ }^{2} \mathrm{H} /{ }^{1} \mathrm{H}\right)_{\mathrm{i}} \\
\text { Exp. } 1\end{array}$ & $\begin{array}{c}\left({ }^{2} \mathrm{H} /{ }^{1} \mathrm{H}\right)_{\mathrm{i}} \\
\text { Exp. } 2\end{array}$ & $\begin{array}{c}\left({ }^{2} \mathrm{H} /{ }^{1} \mathrm{H}\right)_{\mathrm{i}} \\
\text { Exp. } 3\end{array}$ & $\begin{array}{l}\text { Mean }^{a} \\
\left({ }^{2} \mathrm{H} /{ }^{1} \mathrm{H}\right)_{\mathrm{i}}\end{array}$ & $\mathrm{SD}^{b}$ & $\begin{array}{c}\text { Mean by site }{ }^{c} \\
\qquad\left({ }^{2} \mathrm{H} /{ }^{1} \mathrm{H}\right)_{\mathrm{i}}\end{array}$ & SD & $\left({ }^{2} \mathrm{H} /{ }^{1} \mathrm{H}\right)_{\mathrm{i}}^{e}$ & SD \\
\hline 2 & 147.5 & 158.7 & 143.5 & 149.9 & 7.9 & \multirow{2}{*}{141.3} & \multirow{2}{*}{-} & \multirow{2}{*}{141.3} & \multirow{2}{*}{2.5} \\
\hline $2^{\prime}$ & 135.1 & 123.9 & 139.1 & 132.7 & 7.9 & & & & \\
\hline 3 & 140.3 & 148.1 & 140.1 & 142.8 & 4.6 & \multirow{2}{*}{126.5} & \multirow[b]{2}{*}{-} & \multirow{2}{*}{126.5} & \multirow{2}{*}{4.4} \\
\hline $3^{\prime}$ & 112.7 & 104.9 & 112.9 & 110.2 & 4.6 & & & & \\
\hline $4^{i}$ & 129.0 & 130.1 & 118.6 & 125.9 & 6.3 & 125.9 & 6.3 & \multirow{4}{*}{$119.9^{f}$} & \multirow{4}{*}{1.7} \\
\hline 5 & 101.9 & 104.4 & 113.6 & 106.6 & 6.2 & 106.6 & 6.2 & & \\
\hline 6 & 127.8 & 135.1 & 140.8 & 134.6 & 6.5 & 134.6 & 6.5 & & \\
\hline 7 & 113.5 & 105.0 & 112.8 & 110.4 & 4.7 & 110.4 & 4.7 & & \\
\hline 8 & 136.3 & 132.1 & 140.9 & 136.4 & 4.4 & \multirow{2}{*}{120.9} & \multirow{2}{*}{2.9} & \multirow[b]{2}{*}{$140.7^{g}$} & \multirow{2}{*}{2.0} \\
\hline $8^{\prime}$ & 103.8 & 104.8 & 107.2 & 105.3 & 1.8 & & & & \\
\hline 9 & 73.7 & 64.6 & 68.3 & 68.9 & 4.6 & 68.9 & 4.6 & \multirow[b]{2}{*}{$99.8^{h}$} & \multirow[b]{2}{*}{2.0} \\
\hline 10 & 143.1 & 146.6 & 138.7 & 142.8 & 4.0 & 142.8 & 4.0 & & \\
\hline 11 & 98.6 & 98.6 & 98.6 & 98.6 & - & 98.6 & - & 98.6 & 2.1 \\
\hline 12 & 108.1 & 107.2 & 113.9 & 109.7 & 3.6 & 109.7 & 3.6 & \multirow[b]{2}{*}{$99.8^{h}$} & \multirow[b]{2}{*}{2.0} \\
\hline 13 & 74.3 & 80.8 & 78.3 & 77.8 & 3.3 & 77.8 & 3.3 & & \\
\hline 14 & 146.9 & 142.7 & 141.7 & 143.7 & 2.8 & \multirow{2}{*}{160.5} & \multirow{2}{*}{2.9} & \multirow[b]{2}{*}{$140.7^{g}$} & \multirow[b]{2}{*}{2.0} \\
\hline $14^{\prime}$ & 175.8 & 183.2 & 173.0 & 177.3 & 5.3 & & & & \\
\hline 15 & 83.5 & 84.3 & 87.6 & 85.1 & 2.2 & \multirow{2}{*}{127.0} & \multirow{2}{*}{1.0} & \multirow{4}{*}{$119.9^{f}$} & \multirow{4}{*}{1.7} \\
\hline $15^{\prime}$ & 171.4 & 171.0 & 164.2 & 168.9 & 4.1 & & & & \\
\hline $16^{i}$ & 122.9 & 121.7 & 117.0 & 120.6 & 3.1 & 120.6 & 3.1 & & \\
\hline $17^{i}$ & 122.9 & 121.7 & 117.0 & 120.6 & 3.1 & 120.6 & 3.1 & & \\
\hline 18 & 119.0 & 119.0 & 119.0 & 119.0 & - & 119.0 & - & 119.0 & 1.9 \\
\hline \multicolumn{10}{|c|}{$\begin{array}{l}{ }^{a} \text { Mean values from Exp. } 1 \text { to Exp } 3 .{ }^{b} \text { Standard Deviation. }{ }^{c} \text { Mean values by site }{ }^{d} \text { Mean of standard deviations (from column } \\
\text { 6). }{ }^{e} \text { Values given are the mean of }\left({ }^{2} \mathrm{H} / 1 \mathrm{H}\right)_{\mathrm{i}} \text { ratios determined from three NAD } 1 \mathrm{D} \text { experiments. }{ }^{f} \text { Deuterium sites } 4-7 \text { and } 15 \\
17 \text { resonate at the same frequency. }{ }^{g} \text { Deuterium sites } 8 \text { and } 14 \text { resonate at the same frequency. }{ }^{h} \text { Deuterium sites } 9,10,12 \text { and } \\
13 \text { resonate at the same frequency. }{ }^{i} \text { Due to the small spectral enantiodiscrimination and large peak overlapping observed on } \\
\text { NAD spectra, the measurement of }\left({ }^{2} \mathrm{H} /{ }^{1} \mathrm{H}\right)_{\mathrm{i}} \text { ratios for each enantiomeric isotopomers cannot be performed accurately. }\end{array}$} \\
\hline
\end{tabular}


Table SI-4. Composition of liquid-crystalline NMR samples

\begin{tabular}{|c|c|c|c|c|c|c|c|c|c|}
\hline Solute & Polymer & $\begin{array}{c}D p^{a} \text { of } \\
\text { polypeptide }\end{array}$ & $\begin{array}{c}M w^{b} \text { of } \\
\text { polypeptide }\end{array}$ & Co-solvent & $\begin{array}{c}\text { Polymer } \\
/ \mathrm{mg}^{\mathrm{c}}\end{array}$ & $\begin{array}{l}\text { Solute } \\
/ m g^{c}\end{array}$ & $\begin{array}{c}\text { Co-solvent } \\
/ \mathrm{mg}^{\mathrm{c}}\end{array}$ & $\begin{array}{c}\text { \% of polymer } \\
\text { in weight }\end{array}$ & Sample \\
\hline 1 & PBLG & 782 & 171300 & $\mathrm{CHCl}_{3}$ & 100 & 100 & 650 & 11.8 & 4 \\
\hline 1 & PBG & 782 / 914 & $\begin{array}{l}171300 \\
200200\end{array}$ & $\mathrm{CHCl}_{3}$ & $50 / 51$ & 100 & 650 & 11.8 & 5 \\
\hline 2 & PBLG & 782 & 171300 & $\mathrm{CHCl}_{3}$ & 100 & 100 & 649 & 11.8 & 1 \\
\hline 2 & PBG & 782 / 914 & $\begin{array}{l}171300 \\
200200\end{array}$ & $\mathrm{CHCl}_{3}$ & $50 / 51$ & 100 & 650 & 11.8 & 2 \\
\hline 2 & PBDG & 914 & 200200 & $\mathrm{CHCl}_{3}$ & 100 & 100 & 649 & 11.8 & 3 \\
\hline 3 & PBLG & 782 & 171300 & $\mathrm{CHCl}_{3}$ & 100 & 100 & 650 & 11.8 & 6 \\
\hline 3 & PBG & 782 / 914 & $\begin{array}{l}171300 \\
200200\end{array}$ & $\mathrm{CHCl}_{3}$ & $50 / 51$ & 100 & 651 & 11.8 & 7 \\
\hline 4 & PBLG & 782 & 171300 & $\mathrm{CHCl}_{3}$ & 100 & 100 & 651 & 11.8 & 8 \\
\hline 4 & PBG & 782 / 914 & $\begin{array}{l}171300 \\
200200\end{array}$ & $\mathrm{CHCl}_{3}$ & $50 / 51$ & 100 & 650 & 11.8 & 9 \\
\hline
\end{tabular}




$$
\text { - } 13 \text { - }
$$

